\section{Adalimumab in Crohn's disease and symptomatic small bowel strictures}

We thank Sonambekar et $a l^{1}$ for their pertinent remarks, which raised the problem of some errors in our manuscript $^{2}$ and gave us the opportunity to correct them: (1) the length of the strictures on MRI is in centimetres and not in millimetres (table 3); (2) it is noted that among the 97 patients, three had L2 diseases (table 2). After checking each case, two patients had L3 disease and one patient had L1 disease. (3) Among the causes of failure of treatment, a part of sentence was cut-off in the part 'primary and secondary endpoints'. The complete sentence goes as follows: thirty-five patients failed to achieve success for the following reasons: 14 needed corticosteroids after week 8 , two patients were switched to infliximab, eight patients underwent an intestinal resection, two patients had an endoscopic dilation, 10 patients had a severe adverse effect leading to adalimumab discontinuation, two patients interrupted adalimumab treatment and five patients withdrew from the study (four were lost to follow-up and one withdrew consent). Thus, only two patients were switched to infliximab.

We also agree with the authors that the Crohn's disease obstructive score is not yet validated and requires validation and simplification, and the first aspect was underlined in the manuscript.

Yoram Bouhnik, ${ }^{1}$ Jean-Yves Mary ${ }^{2}$

${ }^{1}$ Gastroentérologie, $\mathrm{MICl}$ et Assistance Nutritive, Hôpital Beaujon, Clichy, France

${ }^{2}$ UMR-S-1153 Inserm, Denis Diderot - Paris 7

university, Hôpital Saint-Louis, Paris, France

Correspondence to Dr Yoram Bouhnik, Gastroentérologie, MICl et Assistance Nutritive, Hôpital Beaujon, 92110 Clichy, France; yoram.bouhnik@gmail. com

Contributors JYM and YB have written and verified this letter.

Competing interests None declared.

Patient consent Obtained.

Provenance and peer review Not commissioned; internally peer reviewed.

(C) Article author(s) (or their employer(s) unless otherwise stated in the text of the article) 2018. All rights reserved. No commercial use is permitted unless otherwise expressly granted.

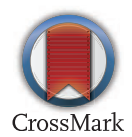

To cite Bouhnik Y, Mary J-Y. Gut 2018;67:199
Received 3 May 2017

Accepted 8 May 2017

Published Online First 10 June 2017

\section{Sinked}

http://dx.doi.org/10.1136/gutjnl-2017-314124

Gut 2018;67:199. doi:10.1136/gutjnl-2017-314431

\section{REFERENCES}

1 Sonambekar AA, Desai DC, Joshi A, et al. Adalimumab in Crohn's strictures - the CREOLE study. Gut 2018;67:198.

2 Bouhnik Y, Carbonnel F, Laharie D, et al. GETAID CREOLE Study Group. Efficacy of adalimumab in patients with Crohn's disease and symptomatic small bowel stricture: a multicentre, prospective, observational cohort (CREOLE) study. Gut 2018;67:53-60. 